\title{
Construction and Validation of Physics Aptitude Test as an Assessment Tool for Senior Secondary School Students
}

\author{
Patrick Uzo Osadebe $\left(\mathbb{D}^{1,{ }^{*}}\right.$, Chukuka Prince Nwabeze ${ }^{1}$
}

\author{
${ }^{1}$ Department of Guidance and Counselling, Delta State University, Abraka, Nigeria
}

\begin{abstract}
The purpose of the study was to construct and validate a Physics Aptitude Test (PAT) for senior secondary schools. The test was designed primarily as an assessment tool for senior secondary school students who have aptitude for Physics. Four research questions guided the study. It was an instrumentation study designed to produce an assessment tool for senior secondary school students. A sample of 200 students was randomly selected through stratified random sampling technique. The data collected were analysed to determine the validity of the test, item validity through item analysis and reliability of the Physics Aptitude Test. The findings revealed that the Physics Aptitude Test (PAT) has adequate face and content validities. It is made up of 50 items. The difficulty and Discrimination indices were appropriate because they are within the standard range of indices for the test. Difficulty indices range from 0.30 to 0.70 , Discrimination indices range from .30 to 0.44 . A reliability coefficient of 0.94 was obtained through Kuder Richardson formula 20 as a measure of internal consistency. Since the Physics Aptitude Test (PAT) was highly valid and reliable, it was recommended that it should always be used as an assessment tool for determining the aptitude of senior secondary school students in Physics.
\end{abstract}

\section{ARTICLE HISTORY}

Received: 26 March 2018

Revised: 13 May 2018

Accepted: 29 May 2018

\section{KEYWORDS}

Construction,

Validation,

Physics,

Aptitude Test

\section{INTRODUCTION}

Education in Nigeria, before the coming of Western Education was mostly oral and informal. Assessment of the informal or traditional education was mainly oral. Written test or formal examination had no place in the evaluation (Ohuche \& Akeju, 1988). The advent of Western education in Nigeria gave birth to formalized mode of testing and examination in the educational system. These examinations are in two forms, internal and external examinations. The internal examinations are test items that are designed and administered within the school such as terminal examinations, promotion examinations and so on, while the external examinations are those examinations conducted by public examination bodies which are external to the students for the purpose of certification, placement, and job opportunities. Some of these bodies include the West African Examination Council (WEAC), State Ministry of

CONTACT: Patrick. U. Osadebe $₫$ drosadebeuzo@gmail.com P. O. BOX 71, ABRAKA, DELTA STATE, NIGERIA 
Education, Joint Admission and Matriculations Board (JAMB), National Examination Council of Nigeria (NECO).

According to Egbule (2002), the term test connotes a common set of tasks or a presentation of a standard set of questions to be answered. Based on the answers provided to the series of questions we obtain a measure that is subject to evaluation. Therefore, a test can be defined as any kind of procedure or device for measuring aptitude, interest, ability, achievement and any other traits or personal attributes.

A test as a set of questions, problems, puzzles, symbols and exercise used to determine a person`s ability, aptitude, knowledge qualification, interest and level of social adjustment. Thus, when you can measure what you are speaking about and express it in numbers, you know something about it; but when you cannot measure it and you cannot express it in numbers, your knowledge about it is of a meagre and an unsatisfactory kind.

Similarly, a test is a sample measure of behaviour from which inferences may be made to a universe of behaviour. This implies that the purpose of most tests is to measure a sample of behaviour. To attempt to measure the entire behaviour at a time may be difficult and farfetched. It is, therefore, only reasonable to measure and obtain a numerical estimate of a single aspect of performance at a time such as language, mathematics, specific aptitude, artistic performance and so on. Therefore, test enables us to measure and understand a concept, sample behaviour or personal attributes. It serves the purpose of selecting students into educational programmes, classification of students, and certification after graduation from one level of education to another, prediction of future performance or potential, verification and evaluation of academic programmes as well as provision of significant data and information for counselling and diagnosis.

\subsection{Review of Literature}

Test construction simply implies a systematic process of assembling test items or the preparation of a test by drawing and compiling series of questions which constitute the task for the students. Test Validation on the other hand, is defined by Gronlund (1976) as a procedure for standardising test items by treating them statistically to remove all source of bias in the process of making them valid, reliable, objective and usable.

Itsuokor (1995) suggested an outline for an effective test construction. He noted that a satisfactory sample is most likely to be obtained when test preparation follows a systematic procedure. He listed the following steps as being useful for this purpose.

a) General statement of instructional objectives;

b) Making an outline of the content to be covered;

c) Preparation of a table of a specification and

d) Constructing test items that measure the objectives in the specified table.

Similarly, Okobia (1990) stated that in constructing and validating a test, certain procedures are followed. As such most measurement and evaluation experts have come to agree that test preparation is a procedural and a systematic process. However, construction and validation strategies may vary from one author to the other depending on the nature of the test. Brown (1983) reports that Educational Testing Services (ETS) recommended typical sequences of construction and validation which is stated as follows:

1. Planning the test

2. Writing the items

3. Pretesting the items

4. Preparing the form

5. Collecting the reliability and validity evidence

6. Developing normative and interpretative materials. 
However, as noted by Osadebe (2001), principles of test construction are the guidelines for developing a test. Test construction is a special area for differential psychologists, test and measurement experts. Test is a valid and reliable instrument. Teachers should be guided in constructing items/test following the principles stated below;

1. Planning

2. Item writing

3. Item analysis-trial testing

4. Composition of item

5. Reliability

6. Printing and Administration

7. Marking and scoring (measurement)

8. Manual

Therefore, the physics teacher, having undergone a course of training in measurement and evaluation should be able to construct, validate, select, administer and score a test as well as interpret the scores generated from tests. There is a notable short fall of test material standardized or normed in Nigerian culture for use in educational services. This situation creates a problem in educational development of the students, for example in Nigeria; it is unfortunate that many of the inappropriate vocation choices are as a result of ignorance and illiteracy on the parts of parents. They have fixed ideas of the course of study, which they would want their children to study, and also the interest of their children in the said course of study (Zhao, 2006). These led students into choosing courses that are either too low or above their mental capacity.

It should be noted that students' low intellectual ability, poor aptitude disposition coupled with low level of aspiration for particular courses like physics have a devastating implication on the students. These problems are as a result of absence of requisite test materials in physics and also in educational and vocational counselling. It should be noted clearly that many failures recorded in the sciences today especially in physics is as a result of wrong selection of courses to be studied.

Therefore, the need for proper matching of aptitudinal disposition of the student is what prompted this study on the construction and validation of Physics aptitude test. Based on this, it is important to emphasize the meaning and relevance of aptitude test in physics. Aptitude generally implies an innate potential of special ability that is capable of predicting future performance (Bannatyne, 1974).

According to Cronbach (1970), aptitude test is a proficiency test that measures ability to perform some task significant in its right. An aptitude test in this regard, is intended to predict success in some occupation or course of training. Cronbach (1970) reported that there are many types of aptitude, musical aptitude, reading aptitude, clerical aptitude, spatial aptitude and numerical aptitude.

Aptitude testing according to Itsuokor (1995), embraces intelligence and achievement, personality, interest and other skills which predispose one to learning. On this basis, he sees aptitude as an ability to learn, and aptitude test assess knowledge, skills and other characteristics that serve to predict learning and success. According to him, aptitude tests cover wide range of human behaviour among which is mechanical aptitude, clerical aptitude, musical aptitude and artistical aptitude. An example of aptitude test commonly used for school educational and vocational counselling is the Differential Aptitude Tests (DAT) which comprises eight distinct sections - verbal reasoning, space - relations including visualization and perception, clerical spread and accuracy, mechanical reasoning, language, spelling and usage (Berk, 1982).Aptitude test is used to investigate not only what a student can do but also what he does. Therefore, aptitude test is used to forecast success in future assignment or occupation. Physics is a physical 
science subject that is concerned mainly with matter as it relates to energy. It has many applications in other fields, for example in chemistry, biology, pharmacy, engineering and other related fields or disciplines. It should be noted that physics is one of the subjects on which modern technology is based. There is the need therefore to lay a solid foundation in the subject by way of developing instrument that can be used to predict or forecast one's success on the subject in future. However, the major reason for this study is to make the students ready for their future. This will be achieved by proper planning and adequate making, and choosing the right so as to properly adjust, or ignore a job. Therefore, the need for proper career planning at entrance into the senior secondary school becomes very important.

Agbola (1990) carried out a study on construction and validation of Mathematics Achievement Test for JSS3 students in Ondo State. He used 50 items in his final test. He involved both rural and urban schools. His calculated $t$ - value was 7.74 which were greater than the 1.96, the critical value at 0.05 level of significance. He found out that there was a significant difference between the scores obtained by the students located in the urban and rural areas in the Ondo state JSC Examinations. Students in the rural areas perform better than the students in the urban areas.

Irighweferhe (2008) carried out a study on construction, validation, and standardization of mathematics achievement test for senior secondary school students in Delta State of Nigeria. The items for the test were drawn from the National curriculum for senior secondary school Mathematics. The items covered the following areas, number and Numeration, Algebraic processes, Plan Geometry, Trigonometry, menstruation and statistics and probability. The constructed test was administered to a sample of 1000 SS3 students in the 2007/2008 academic session selected through stratified random sampling. The result obtained from student's performance was norm using standard score of Z-scores and T-scores. The norm profile of performance of student across gender, location, subject combination and school type indicated that there was a relationship performance of student among the above mention variables. It was therefore recommended that the standardized mathematics achievement test should be used in preparing and assessing the performance of students preparing for the senior secondary school certificate examination and at same time gaining insight into their potentials in mathematics. Test manuals for the Standardized Mathematics Achievement Test (SMAT) was also prepared.

Akaezue (2009) carried out a study on construction and validation physics aptitude test in senior secondary school in Sapele Local Government Area of Delta State. To achieve this purpose four research question were drawn to guide the study. It is an instrumentation study. The instrument developed is called physics aptitude test. A sample of hundred students was used to determine the item difficulty, discriminatory index validity and reliability of the physics aptitude test. The test has content validity; a reliability of 0.75 was obtained through the use of Kuder - Richardson formula 20. The test has a standard error of measurement of 3.15. The difficulty level of the test ranges from 0.325 to 0.855 while the discriminatory level ranges from 0.15 to 0.48 . The researcher found out that the test has high content validity, the items of the test are suitable in terms of its difficulty and discriminatory indices and also the test and its entire subsections have high degree of internal consistency with a low standard error of measurement.

The review carried out in this study indicated that some studies have been done in test construction and validation in many subjects such as Chemistry, Biology, Geography, Economics, Mathematics and Integrated Science but not much, known to the researchers, has been done in Physics in Delta State in recent times. This is the gap the study covered. 


\subsection{Purpose of the Study}

The main purpose of the study was to construct and validate Physics Aptitude Test (PAT). Specifically, the study determined the following:

1. Validity of the Physics Aptitude Test

2. Difficulty index of each item of the Physics Aptitude Test

3. Discrimination index of each item of the Physics Aptitude Test

4. Reliability of the Physics Aptitude Test

\subsection{Research Questions}

The study was guided by the following research questions:

1. What is the validity of Physics Aptitude Test?

2. What is the difficulty index of each item of the Physics Aptitude Test?

3. What is the discrimination index of each item of the Physics Aptitude Test?

4. What is the reliability of Physics Aptitude Test?

\section{METHOD}

The design of this study is instrumentation. It involves the construction and validation of Physics Aptitude Test (PAT). It is designed for selecting senior secondary school students who have ability for Physics.

The population for this study comprises public Senior Secondary 1(SSI) students in 2014/2015 academic session in Delta North Senatorial District of Delta State. The population consists of 5,760 SSI students from Public Secondary Schools in Delta North Senatorial District of Delta State (Ministry of Education, Delta State. 2014).

From the population, a total of 200 students in SS1 were sampled for the study in Delta North Senatorial District of Delta State. The sampling technique adopted for this study is the stratified sampling and simple random sampling technique.

According to Nworgu (2003), stratified sampling ensures greater representativeness of the sample relative the population and guarantees that minority constituents of the population are represented in the sample. The sample characteristics therefore are better approximation (estimates) of the population characteristics and the associated sampling error is correspondingly reduced. Elements are drawn randomly from each in such a way that the relative proportions of the strata in the resultant sample are the same as in the parent population. The relative contribution of each stratum in the population is exactly its relative contribution in the sample. The sample, therefore, will possess specified characteristics in exactly the same proportion as those characteristics exist in the parent population.

Random sampling is therefore the selection of sample subjects by chance from population and is therefore not influenced by other factors or considerations. The simple random sampling technique ensures that every object, event or individuals in the population has a chance of being drawn for the sample.

The instrument for the research is Physics Aptitude Test (PAT). The instrument is made up of items drawn from SS1 Physics. It was generated in such a way that the cognitive aspects of the students' behaviour were included, and various aspects/component of aptitude test were reflected such as numerical aptitude which is in the first section and it has a total of ten(10) questions, followed by the verbal section which also has a total of ten (10) questions. Next to the verbal aptitude section is the quantitative aptitude section which has a total of 15 questions. The last section of this test is the mechanical aptitude test section which also has a total of fifteen (15) questions. 
Summarily, 100 questions were constructed but fifty (50) questions were eliminated from the generated 100 items after item analysis; that is the difficulty level and item discriminative index. After the item analysis and modification of the items, fifty (50) items were selected for the final test. These Fifty (50) questions formed the various sections of the aptitude test. Each item has four (4) options lettered; A, B, C and D. One out of the four (4) options is correct while the other three are treated as distracters.

Validity is one of the most essential psychometric properties of a test. The validity of a test is the extent to which a test measures what it is supposed to measure. It refers to the extent to which the results of an evaluation procedure serve the particular uses for which they are intended (Gronlund, 1976). In order to establish the content validity of the test items, a table of specifications was drawn. This shows the various types of aptitude test considered, and the total number of generated test items. In addition, two specialists in the field of physics and two other specialists in measurement and evaluation were used. The specialists carefully examined the generated test items, made useful suggestions and approved the try out test.

The Kuder- Richardson formula 20 (KR20) was used in establishing a measure of internal consistency of the test. The test was administered to 30 students that were randomly selected from the population, for the purpose of the reliability. A reliability index of 0.94 was obtained from the computation.

To collect the data for the research, the generated test items (Physics Aptitude Test question) was administered to 200 students for the purpose of item analysis. This was done with the assistance of the teachers and cooperation of the management of the selected schools. The instrument was timed and a total of one hour was allowed for the test. The students were stopped at the stipulated time. At the end of the test the researcher collected the students' response sheet. The test items were administered on conducive environment devoid of any form of examination malpractice.

In scoring the test, each item that was correctly answered attracted one (1) mark or one (1) point while wrongly answered items attracted zero (0) mark. The test rates the performance of the testees over hundred (100) points or marks. This was used to select students who are capable of studying physics. It should be noted here that for ease of computation, a multiplying factor of 2 was used to multiply the scores at the end of scoring the testees.

However, the item difficulty and discriminating indices were calculated for the 100 items to select 50 items. The students' sheets were re-arranged from the highest to the lowest. The upper group of $27 \%$ and lower group of $27 \%$ were selected and used for the item analysis.

Items with difficulty indices ranging from 0.30 to 0.70 were included (accepted) for the fina \#+1 test while others below 0.30 and above 0.70 were discarded (rejected) as a result of being too difficult or too easy respectively. The item discrimination index (D) ranged from 0.30 to 0.44 and this formed the bench mark for accepting items regarding discrimination indices for the final test.

\section{RESULTS}

Research Question One: What is the validity of Physics Aptitude Test?

In order to provide answer to the first research question, a table of specifications was constructed. The test blue print was drawn to ascertain the extent of the content validity of the Physics Aptitude Test (PAT). The table is presented below. 
Table 1. A Table of Specifications evaluating the extent of the Content Validity of the 50 items of PAT.

\begin{tabular}{|c|c|c|c|c|c|c|c|}
\hline & \multicolumn{7}{|c|}{ COGNITIVE LEVEL (BEHAVIOURAL OBJECTIVE) } \\
\hline $\begin{array}{l}\text { Content } \\
\text { Area }\end{array}$ & $\begin{array}{l}\text { Know } \\
10 \%\end{array}$ & $\begin{array}{l}\text { Comp } \\
10 \%\end{array}$ & $\begin{array}{l}\text { Application } \\
20 \%\end{array}$ & $\begin{array}{l}\text { Analysis } \\
20 \%\end{array}$ & $\begin{array}{l}\text { Synthesis } \\
20 \%\end{array}$ & $\begin{array}{l}\text { Evaluation } \\
20 \%\end{array}$ & $\begin{array}{l}\text { Total } \\
100 \%\end{array}$ \\
\hline $\begin{array}{l}\text { Numerical } \\
\text { Aptitude } \\
20 \%\end{array}$ & 1 & 1 & 2 & 2 & 2 & 2 & 10 \\
\hline $\begin{array}{l}\text { Verbal } \\
\text { Aptitude } \\
20 \%\end{array}$ & 1 & 1 & 2 & 2 & 2 & 2 & 10 \\
\hline $\begin{array}{l}\text { Quantitative } \\
\text { Aptitude } \\
30 \%\end{array}$ & 1 & 2 & 3 & 3 & 3 & 3 & 15 \\
\hline $\begin{array}{l}\text { Mechanical } \\
\text { Aptitude } \\
30 \%\end{array}$ & 2 & 1 & 3 & 3 & 3 & 3 & 15 \\
\hline Total & 5 & 5 & 10 & 10 & 10 & 10 & 50 \\
\hline
\end{tabular}

As seen on Table 1, the table of specifications clearly reflects the various content areas in Physics that were considered in this study which helped to establish a high content validity for the Physics Aptitude Test. Therefore, the Physics Aptitude Test has a high content validity because there was a wide content coverage.

In addition to the table of specifications, the researchers also presented the test items to other experience Physics teachers, project supervisor and two Measurement and Evaluation Experts who also established the correctness, adequateness and appropriateness of the items in the constructed test. The face validity of the test was also established. It describes the appearance of the test. It refers to how real the items of a test are to test takers; the cosmetics to the format for presenting or reporting the test items, the typing and general outlook of the test. Test?

Research Question 2: What is the difficulty index of each item of the Physics Aptitude

The test constructors used the difficulty index to select the suitable items that are appropriate to be included in the final test. These items were selected from the initial items generated for the trial testing. Items with index of $0.30-0.70$ were selected for the difficulty level

Table 2. Items and their Difficulty indices $(\mathrm{P})$

\begin{tabular}{cll}
\hline S/N & \multicolumn{1}{c}{ ITEMS (NUMERICAL APTITUDE TEST) } & $\boldsymbol{P}$ \\
\hline 1. & $\begin{array}{l}\text { A boy of mass } 50 \mathrm{~kg} \text { runs up a set of steps of total height } 3.0 \mathrm{~m} \text {. Find the work done } \\
\text { against gravity. }\end{array}$ & 0.55 \\
2. & $\begin{array}{l}\text { A car travels at an average speed of } 100 \mathrm{kmh}^{-1} \text {, what distance does it cover in } \\
\text { 5minutes? }\end{array}$ & 0.54 \\
3. & $\begin{array}{l}\text { An object of mass } 5 \mathrm{~kg} \text { is moving at a constant velocity of } 15 \mathrm{~ms}^{-1} \text {, calculate its } \\
\text { kinetic energy. }\end{array}$ & 0.60 \\
4. & $\begin{array}{l}\text { A boy of mass } 10 \mathrm{~kg} \text { climbs up } 10 \text { steps each of height } 0.2 \mathrm{~m} \text { in } 20 \text { seconds. Calculate } \\
\text { the power of the body. }\end{array}$ & 0.61 \\
5. & $\begin{array}{l}\text { Three resistor of resistance } 1 \Omega, 2 \Omega \text { and } 4 \Omega \text { are connected in series find the } \\
\text { equivalent resistance of the combination. }\end{array}$ & 0.63 \\
6. & $\begin{array}{l}\text { Find the resistance of a wire of length } 0.65 \mathrm{~m} \text {, radius } 0.2 \mathrm{~mm} \text { and resistivity } 3 \times 10^{-} \\
\text {6ohm-metre. }\end{array}$ & 0.59
\end{tabular}


7. A force of $0.8 \mathrm{~N}$ stretches an elastic spring by $2 \mathrm{~cm}$. Find the elastic constant of the 0.62 spring.

8. A spring is stretches $40 \mathrm{~mm}$ by a force $15 \mathrm{~N}$ what is the work done by the force? 0.55

9. A change of 10 coulombs flows round a circuit in 2seconds. what is the current? 0.59

10. A boy moves a load of $10 \mathrm{~N}$ at a distance of 5 metres.calculate the w0sork done. 0.63

\section{ITEMS (VERBAL APTITUDE TEST)}

11. Which of the following is a fundamental unit?

12. Which of the units of the following physical quantities are not derived? 0.62

13. What is the best instrument for measuring the diameter of a meter rod? 0.47

14. Which among the following substance is a non- conductor? 0.59

15. Which of the following is not a consequence of a force field? 0.61

16. The slope of a straight line displacement -time graph indicates 0.52

17. Under which of the following conditions is work done 0.60

18. A room is heated by a means of a charcoal fire. A man standing away from the fire 0.62 is warmed by

19. On which of the following is the design of the thermostat of an electric iron based? 0.53

20. Which of the following surface will absorb radiant heat energy best? 0.65

ITEMS (QUANTITATIVE APTITUDE TEST)

21. An effort of $10 \mathrm{~N}$ was used in lifting a load of $500 \mathrm{~N}$.calculate the mechanical 0.49 advantage used in lifting the load

22. A load of $10 \mathrm{~N}$ was pushed through a height of 2 meters.calculate the work done in 0.55 pushing the load.

23. A man lifted a bag of cement of mass $50 \mathrm{~kg}$ through a height of 2 meters.If the 0.57 acceleration due to gravity is $10 \mathrm{~ms}^{-2}$. Calculate the energy used in lifting the load

24. Express 4000J in kilojoules

25. 3 mega joules is equivalent to ------ joule?

26. How many minutes do we have in 2hours?

0.62

27. The speed of a bus increases uniformly from $15 \mathrm{~ms}^{-1}$ to $60 \mathrm{~ms}^{-1}$ in 20 seconds. 0.54 Calculate the average speed.

28. A man of mass 50kg ascends a flight of stairs $5 \mathrm{~m}$ high in 5 seconds. If acceleration 0.59 due to gravity is $10 \mathrm{~ms}^{-2}$, the power expended is?

29. A body of mass $10 \mathrm{~kg}$ accelerate at $2 \mathrm{~ms}^{-2}$ what is the force in Newton (take; $\left.\mathrm{F}=\mathrm{ma}\right) \quad 0.63$

30. Two bodies $x$ and $y$, undergo a distance of $30.25 \mathrm{~km}$ and $50.75 \mathrm{~km}$ respectively. What 0.57 is the total distance made by $\mathrm{x}$ and $\mathrm{y}$

31. Convert $50 \mathrm{~cm}$ to metres 0.58

32. A metre rule was measured to be $100.02 \mathrm{~cm}$. What is the error in the measurement? 0.49

33. A body has a mass $40 \mathrm{~kg}$ and velocity $5 \mathrm{~m} / \mathrm{s}$, calculate the energy possessed by this 0.63 body?

34. A girl lift a load of $2 \mathrm{~kg}$ through a height $10 \mathrm{~m}$. what is the work done against gravity 0.61

35. A machine has a mechanical advantage 0.2 and load of 5000N.Calculate the effort 0.59 of the machine

\section{ITEMS (MECHANICAL APTITUDE TEST)}

36. A machine has an efficiency of $60 \%$.If the machine is required to overcome a load 0.61 of $30 \mathrm{~N}$ with a force of $20 \mathrm{~N}$, calculate its velocity ratio

37. Which among the following is not a consequence and application of expansion? $\quad 0.53$

38. The bimetallic strip has its application on the following appliance except 0.50

39. A screw that is rotated forward through one revolution will move a distance equal 0.58 to

40. From the diagram below, one can conclude that

A

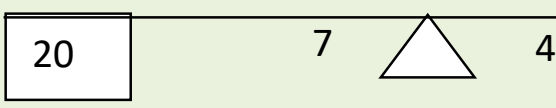

20

41. On which of the following is the design of the thermostat of an electric iron based? 0.56 
42. If a load of $5000 \mathrm{~N}$ could be lifted up by an effort of $100 \mathrm{~N}$, what is the mechanical 0.53 advantage of the machine?

43. A building can be adequately protected from lighting by ......... 0.55

44. A rocket is burning fuel at the rate of $200 \mathrm{gs}^{-1}$ and ejecting all the gas in one direction 0.59 at the rate of $400 \mathrm{~ms}^{-1}$. what is the maximum weight the rocket can have if it is going to move vertically upwards?

45. Efficiency of a machine is defined by ..........?

46. Which principle does the lever operates? 0.53

47. A machine has a velocity ratio 5 and is $80 \%$ efficient. What effort would be needed 0.50 to lift a load of $200 \mathrm{~N}$ with the aid of this machine?

48. The velocity ratio of inclined plane is given by 0.54

49. Which of the following is not an example of levers of the first order? 0.57

50. The ideal method of reducing friction in a machine ........? ? 0.55

Table 2 shows the difficulty indices of 50 items for the various component of the Physics aptitude test. The acceptable indices ranged from 0.30 to 0.70 . The Numerical Physics Aptitude Test items ranged from 0.54 to 0.63 , Verbal Physics Aptitude test items ranged from 0.47 to 0.65, Quantitative Aptitude test items ranged from 0.49 to 0.67 and Mechanical Physics Aptitude test items ranged from 0.50 to 0.61 . The indices were established during item analysis which helped to ensure high item validity for each Physics test item.

Research Question Three: What is the discrimination index of each item of the Physics Aptitude Test?

This research question was answered using the item analysis. The discriminating indices help to refine test items. The indices help to measure the extent to which items discriminate between high and low achievers (students).

Table 3. Items and their Discriminatory level (D)

\section{S/N ITEMS (NUMERICAL APTITUDE TEST)}

$D$

1. A boy of mass $50 \mathrm{~kg}$ runs up a set of steps of total height $3.0 \mathrm{~m}$. Find the work done 0.41 against gravity.

2. A car travels at an average speed of $100 \mathrm{kmh}^{-1}$, what distance does itCover in 0.44 5minutes?

3. An object of mass $5 \mathrm{~kg}$ is moving at a constant velocity of $15 \mathrm{~ms}^{-1}$, calculate its 0.41 kinetic energy.

4. A boy of mass $10 \mathrm{~kg}$ climbs up 10 steps each of height $0.2 \mathrm{~m}$ in 20 seconds. Calculate 0.33 the power of the body.

5. Three resistor of resistance $1 \Omega, 2 \Omega$ and $4 \Omega$ are connected in series find the 0.41 equivalent resistance of the combination.

6. Find the resistance of a wire of length $0.65 \mathrm{~m}$, radius $0.2 \mathrm{~mm}$ and resistivity $3 \times 10^{-6} 0.44$ ohm-metre.

7. A force of $0.8 \mathrm{~N}$ stretches an elastic spring by $2 \mathrm{~cm}$. Find the elastic constant of the 0.35 spring.

8. A spring is stretches $40 \mathrm{~mm}$ by a force $15 \mathrm{~N}$ what is the work done by the force? $\quad 0.32$

9. A change of 10 coulombs flows round a circuit in 2 seconds. what is the current? 0.37

10. A boy moves a load of $10 \mathrm{~N}$ at a distance of 5metres.calculate the work done. 0.33

11. Which of the following is a fundamental unit? 0.30

12. Which of the units of the following physical quantities are not derived? 0.39

13. What is the best instrument for measuring the diameter of a meter rod? 0.35

14. Which among the following substance is a non- conductor? 0.37

15. Which of the following is not a consequence of a force field? 0.41

16. The slope of a straight line displacement -time graph indicates 0.33

17. Under which of the following conditions is work done 0.32 
18. A room is heated by a means of a charcoal fire. A man standing away from the fire 0.35 is warmed by

19. On which of the following is the design of the thermostat of an electric iron based? 0.39

20. Which of the following surface will absorb radiant heat energy best? 0.37

ITEMS (QUANTITATIVE APTITUDE TEST)

21. An effort of $10 \mathrm{~N}$ was used in lifting a load of $500 \mathrm{~N}$.calculate the mechanical 0.37 advantage used in lifting the load

22. A load of $10 \mathrm{~N}$ was pushed through a height of 2 meters.calculate the work done in 0.39 pushing the load.

23. A man lifted a bag of cement of mass $50 \mathrm{~kg}$ through a height of 2 meters.If the 0.33 acceleration due to gravity is $10 \mathrm{~ms}^{-2}$. Calculate the energy used in lifting the load

24. Express $4000 \mathrm{~J}$ in kilo joule

25. 3 mega joules is equivalent to ----- joule? 0.41

26. How many minutes do we have in 2hours? 0.43

27. The speed of a bus increases uniformly from $15 \mathrm{~ms}^{-1}$ to $60 \mathrm{~ms}^{-1}$ in 20 secoSnds. 0.33 Calculate the average speed.

28. A man of mass $50 \mathrm{~kg}$ ascends a flight of stairs $5 \mathrm{~m}$ high in 5 seconds. If acceleration 0.37 due to gravity is $10 \mathrm{~ms}^{-2}$, the power expended is?

29. A body of mass $10 \mathrm{~kg}$ accelerate at $2 \mathrm{~ms}^{-2}$ what is the force in Newton (take; $\mathrm{F}=\mathrm{ma}$ ) 0.41

30. Two bodies $x$ and $y$, undergo a distance of $30.25 \mathrm{~km}$ and $50.75 \mathrm{~km}$ respectively. What 0.33 is the total distance made by $\mathrm{x}$ and $\mathrm{y}$

31. Convert $50 \mathrm{~cm}$ to meters 0.39

32. A metre rule was measured to be $100.02 \mathrm{~cm}$. What is the error in the measurement? 0.35

33. A body has a mass $40 \mathrm{~kg}$ and velocity $5 \mathrm{~m} / \mathrm{s}$, calculate the energy possessed by this 0.33 body?

34. A girl lift a load of $2 \mathrm{~kg}$ through a height $10 \mathrm{~m}$. what is the work done against gravity 0.37

35. A machine has a mechanical advantage 0.2 and load of $5000 \mathrm{~N}$.Calculate the effort 0.44 of the machine

\section{ITEMS (MECHANICAL APTITUDE TEST)}

36. A machine has an efficiency of $60 \%$.If the machine is required to overcome a load 0.41 of $30 \mathrm{~N}$ with a force of $20 \mathrm{~N}$, calculate its velocity ratio

37. Which among the following is not consequence and application of expansion? $\quad 0.39$

38. The bimetallic strip has its application on the following appliance except 0.37

39. A screw that is rotated forward through one revolution will move a distance equal 0.35 to

40. From the diagram below, one can conclude that

A

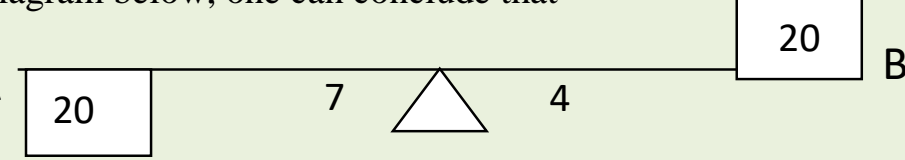

41. On which of the following is the design of the thermostat of an electric iron based?

42. If a load of $5000 \mathrm{~N}$ could be lifted up by an effort of $100 \mathrm{~N}$, what is the mechanical 0.35 advantage of the machine?

43. A building can be adequately protected from lighting by ......... 0.32

44. A rocket is burning fuel at the rate of $200 \mathrm{gs}^{-1}$ and ejecting all the gas in one direction 0.41 at the rate of $400 \mathrm{~ms}^{-1}$. what is the maximum weight the rocket can have if it is going to move vertically upwards?

45. Efficiency of a machine is defined by ..........?

46. Which principle does the lever operates? 0.39

47. A machine has a velocity ratio 5 and is $80 \%$ efficient. What effort would be needed 0.41 to lift a load of $200 \mathrm{~N}$ with the aid of this machine?

48. The velocity ratio of inclined plane is given by 0.37

49. Which of the following is not an example of levers of the first order? 0.33

50. The ideal method of reducing friction in a machine .........? 
Table 3 indicates the discrimination indices of 50 items for the various components or characteristics of Physics aptitude Test. The acceptable indices during item analysis ranged from 0.30 to 0.44 . The discrimination indices of the Numerical Aptitude test item ranged from 0.32 to 0.44 , Verbal Aptitude 0.30 to 0.41 , Quantitative Aptitude 0.33 to 0.44 , and Mechanical Aptitude 0.30 to 0.41 . The item indices were accepted and appropriate for the Physic Aptitude Test (PAT).

Research Question Four: What is the reliability of Physics Aptitude Test?

To give answer to research question four, the reliability of the PAT was estimated using Kuder Richardson formula 20. The formula is stated below:

Table 4. Analysis of Reliability of Physics Aptitude Test.

\begin{tabular}{llccccccccc} 
No of students & No of items & $\Sigma p q$ & $\bar{X}$ & $S D$ & $S D 2$ & $r$ & $r 2$ & $r \%$ & SEM & Decision at .05 \\
\hline 30 & 50 & 9.1801 & 31 & 3.2 & 9.933 & 0.94 & 0.8836 & 94 & 0.78 & High \\
\hline
\end{tabular}

As can be seen from Table 4, an estimate of the PAT reliability using Kuder Richardson formula 20 was established. This approach becomes pertinent because the PAT is a multiple choice objective test with expected response of either pass (1) or fail (0). However, a reliability index of 0.94 was obtained. The result is significant at .05 level of significance which made the instrument (PAT) very suitable for the study. A standard error of measurement (SEM) of 0.78 was obtained. The SEM is low and this confirms that PAT is highly reliable.

\section{DISCUSSION}

The discussion is based on the main findings after answering the research questions. The instrument was validated. Validity is one of the pertinent psychometric properties of an instrument. It refers to the extent to which an instrument measures what it is designed to measure. In establishing the content validity of the instrument, two approaches were adopted. First the use of table of specification was employed. This approach is similar to Osadebe (2001), Irighweferhe (2008), Akpoguma (2008), Akaezue (2009) and Osiobe (2012). The second approach adopted was the use of experts' judgement. The items were presented to experienced physics teachers and measurement and evaluation experts. This provide for the correctness, adequateness and appropriateness of the test. To establish the reliability of the Physics Aptitude Test, Kuder - Richard formula 20 was employed. The use of Kuder - Richard formula 20 was as a result of the fact that the Physics Aptitude Test is a multiple choice objective test with expected response of either pass (1) or fail (0). A reliability coefficient of 0.94 was obtained at 0.05 unlike Oloya (2005) and Onoyumolo (2005), who used split - half method in establishing their reliability.

Furthermore, Irighweferhe (2008) agreed that reliability coefficient of 0.69 is high and adequate. Akazue (2009) in his study, reported reliability coefficient of 0.75 which he judged to be significant for a test. This study has found out that the new instrument (PAT) has a higher reliability of 0.94 which is higher than the above reported ones. The instrument yielded very high internal consistency of scores.

Classical test theory was used in the construction of the Physics Aptitude Test (PAT). This approach is similar to Egbule (1998), Osadebe (2001), Irighweferhe (2008), Akpogumu (2008), Akaezue (2009) and Osiobe (2012). In addition to the classical test theory, a conceptual model was also designed to enhance the quality of the instrument.

The items that made up the instrument (PAT) were selected through the item analysis. Their difficulty indices and discriminating indices were computed. In terms of difficulty 
indices, experts in measurement and evaluation such as Nworgu (2003) reported that an ideal item should have facility index of 0.5 but in real life situation it will range from 0.30 to 0.70 . All items in the instrument are within the range of 0.30 and 0.70 making them very appropriate, suitable and effective. This is similar to Akpoguma (2008) and Osiobe (2012).

The discriminating indices that measure the extent items discriminate between the bright and dull students were also computed. Discriminating index of an item varies from 0.00 to 0.01 . Negative indices are abnormal because they penalised more of the bright students than the dull students; hence they were rejected. Nworgu (2003) agreed that an ideal item should possess discriminating indices of +1 but realistically it should range from +0.03 to 1.00 . In order to include only high-quality items, the researcher used a realistic range of discriminating indices from 0.30 to 1.00 to select the items included in the instrument. This is similar to Akpoguma (2008) and Osiobe (2012).

Conclusively, the Physics Aptitude Test developed by the researchers is a test with high psychometric properties. As such, the test could be used for the selection of secondary school students who have the desire to study physics in their senior secondary schools as well as an assessment tool for the evaluation of learning outcomes.

The items of the test are suitable and appropriate in terms of difficulty and discrimination indices. The test has a high degree of internal consistency with a low standard error of measurement.

\section{ORCID}

\section{Patrick Osadebe(iD https://orcid.org/0000-0002-6365-4285}

\section{REFERENCES}

Agbola, F. (1990). Construction and Validation of Mathematics Achievement Test for J.S.S 3 Students. Unpublished M. Ed. Dissertation, University of Benin, Benin City, Nigeria.

Akaezue, N.N. (2009). Construction and Validation of Physics Aptitude Test for Senior Secondary School Student in Delta State. Unpublished M.Ed. project, Delta State University, Abraka, Delta State.

Akpoguma, J. (2008). Construction and Validation of Mathematics Achievement Test for Senior Secondary School Students in Delta State. Unpublished M.Ed. Project Delta State University, Abraka.

Bannatyne, A. (1974). Diagnosis: A Note on the Recategorization of the Wisc Scaled Scores. Journal of Learning Disorders, 7, 272-273.

Berk, R.A. (1982). Handbook for Detecting Test Bias. Baltimore: John Hopkins University Press.

Brown, F.G. (1983). Principles of Education and Psychological Testing (3rd Edition). Oxford University Press.

Cronbach, L. J. (1970). Essential of Psychological Testing: New York: Steal Press.

Educational Testing Service (1992). The Origin of Educational Testing Service. Princeton, NJ: ETS. En.wikipedia.org/wiki/Educational-Testing-Service.

Egbule, J. F. (2002). Principles of Psychological Testing. Owerri: Whyte and Whyte Publishers.

Egbule, J.F. (1998). Construction and Validation of Differential Aptitude Test (DAT) for Educational and Vocational Counselling. An Unpublished Ph. D thesis, Delta State University Abraka.

Gronlund, E. N. (1976). Measurement and Evaluation in Psychology and Education. New York: Macmillan Publishing Company. 
Irighweferhe, S. U. (2008). Construction, Validation and Standardization of Mathematics Achievement Test for Senior Sate Secondary School Student in Delta State of Nigeria. An Unpublished M.Ed project, Delta State University Abraka, Abraka, Delta State.

Itsuokor, D. E. (1995). Essentials of Test and Measurement. Illorin: Woye and Sons (Nig) Ltd.

Nworgu, B.G. (2003). Educational Measurement and Evaluation, Theory and Practices. Nsukka; University Trust Publishers.

Ohuche, R.O. \&Akeju, S.A. (1988). Continuous Assessment for every Learner. Onitsha: Africana FEP publishers.

Okobia, D.O. (1990). Construction and Validation of Social Studies Achievement Test (SSAT) for SS Students in Selected Secondary Schools in Bendel State. An unpublished M. Ed project, University of Benin, Benin City, Nigeria.

Onoyumolo, L.A. (2005). Construction, Validation of achievement test for Physics for SSS Student in Warri South L.G.A. of Delta State. An unpublished M. Ed project Delta State University, Abraka.

Osadebe, P.U. (2001). Construction and Standardization of an Economics achievement test for senior secondary school students. Unpublished Doctoral thesis, University of Port Harcourt.

Osiobe, G.A. (2012). Construction and Standardization of Geography Objective Test for Senior Secondary Schools in Delta State. Unpublished Ph.D thesis, Delta State University Abraka.

Zhao, Y.Y. (2006). Motivation in Education. International Journal of Engineering Education, $22,1281-1286$. 